\title{
Psychosocial Reaction Patterns to Alopecia in Female Patients with Gynecological Cancer undergoing Chemotherapy
}

\author{
Kazuko Ishida $^{1 *}$, Junko Ishida $^{2}$, Kanda Kiyoko ${ }^{3}$
}

\begin{abstract}
This study aims to clarify the psychosocial reactions of female patients with gynecological cancer undergoing chemotherapy and in the process of suffering from alopecia and to examine their nursing support. The target group comprised female patients who had received two or more cycles of chemotherapy, were suffering from alopecia, and were aged 30-65. Data were collected from semi-structured interviews, conducted from the time the patients were informed by their doctors that they might experience alopecia due to chemotherapy to the time they actually experienced alopecia and until they were able to accept the change. Inductive qualitative analysis was employed to close in on the subjective experiences of the cancer patients. The results showed the existence of six phases in the psychosocial reactions in the process of alopecia: phase one was the reaction after the doctor's explanation; phase two was the reaction when the hair starts to fall out; phase three was the reaction when the hair starts to intensely fall out; phase four was the reaction when the hair has completely fallen out; phase five was the reaction to behavior for coping with alopecia; and phase six was the reaction to change in interpersonal human relationships. The results also made it clear that there are five types of reaction patterns as follows: 1) treatment priority interpersonal relationship maintenance type; 2) alopecia agitated interpersonal relationship maintenance type; 3) alopecia agitated interpersonal relationship reduction type; 4) alopecia denial interpersonal relationship reduction type; and 5) alopecia denial treatment interruption type. It is important to find out which of the five types the patients belong to early during treatment and provide support so that nursing intervention that suits each individual can be practiced. The purpose of this study is to make clear the process in which patients receiving chemotherapy come to accept alopecia and to examine evidence-based nursing care on patients with strong mental distress from alopecia.
\end{abstract}

Keywords: Cancer treatment - hair loss - pattern - breast cancer - uterine cancer

Asian Pac J Cancer Prev, 16 (3), 1225-1233

\section{Introduction}

Alopecia is a side-effect that frequently accompanies chemotherapy (Kanda et al., 1998), and it does not have a direct connection with someone's life being in crisis. There is a tendency to neglect methods for coping with alopecia, because people are aware that once the medical treatment is over, the patient's hair returns (Nahoko and Mitiko, 2009). Moreover, patient who suffer from alopecia due to chemotherapy undertaken in cancer treatments view themselves as a sick person when they look at their reflection in the mirror. This makes them strongly aware that they are a cancer patient (Williams et al., 1999), and it has been pointed out that this impacts their body image. Antiemetic medicine is currently prescribed for a few of the damaging effects of chemotherapy such as nausea, vomiting, and bone marrow suppression, and G-CSF drugs have been shown to have effects on neutropenia caused by chemotherapy (Carelle et al., 2002). However, despite the fact that alopecia is a symptom that increases the patient's suffering, there have been some reports on the effectiveness of scalp creams (Dean and Salmon, 1979; Gregory et al., 1982; Mols et al., 2008; Van der Hurk, et al., 2010; Van der Hurk, et al., 2012; Van der Hurk, et al., 2012; Ekwall et al., 2013; Komen et al., 2013), but there are no established precautionary measures.

Nursing studies that handle alopecia that accompanies chemotherapy researched the change in body image caused by alopecia (Frith et al., 2007), male patient's experience of alopecia (Hamada et al., 2007), the influence on breast cancer patient's quality of life (QOL) due to alopecia resulting from chemotherapy and their awareness regarding alopecia (Hilton et al., 2008; Lemieux et al., 2008; Bernard et al., 2011; Can et al., 2012; Kim et al., 2012).

Batchelor (2001) noted that a patient's loss of hair signifies the loss of hope to live and disappearance of the patient's individuality and attractiveness. Moreover, 
patients who suffer from alopecia resulting from chemotherapy display a decrease in their level of selfrespect (Roe, 2011), and it has been reported that there is a lot of mental damage caused by alopecia (Nolte et al., 2006). As a side-effect of chemotherapy, alopecia brings about a change in appearance, and it has a large impact on the psychosocial aspect of a person including that person's body image.

The addition of outpatient chemotherapy has been authorized since March, 2002 due to the plan of shortening stays in the hospital and the standardization of cancer treatments that was promoted by the Ministry of Health, Labor, and Welfare. Moreover, since 2004, outpatient chemotherapy has been authorized for any institution that has received the approval of the Japan Council for Quality Health Care even if it is not a hospital, thus resulting in a rapid increase in patients who undergo chemotherapy. The system is currently transitioning from patients who undergo chemotherapy being hospitalized to healing in an outpatient setting. Therefore, the balance of a social life is important for the continuation of medical treatment. Coping with the alopecia that accompanies medical treatment is largely dependent on the attitude of the patient themselves and their efforts in order to bring about a change in their lives. Although the mental trauma caused by alopecia has become clear (Keiko et al., 2013), it has not become clear how the patient's psychosocial reaction patterns have changed or how medical care providers can support the patient during the process of alopecia. Therefore, clarifying the patient's psychosocial reaction patterns to the process of alopecia will make it possible to provide suitable nursing support for patients who are undergoing chemotherapy. This support can also be adapted to the target group's viewpoints. Furthermore, it is thought that this will contribute to an increase in the chemotherapy patients' QOL.

This study aims to clarify the psychosocial reactions patterns in the process of suffering from alopecia caused by chemotherapy. This will be done by focusing on female patients with gynecological cancer who are undergoing chemotherapy.

\section{Definition of Terms}

\section{Psychosocial reaction}

Psychosocial reactions are defined as the reactions that accompany the awareness of bodily changes caused by a person's disease as well as those that influence their mind. In other words, these reactions are related to the important people in the patient's own lives, to their selfimage, and to their own emotions. This study includes in the definition the thoughts, feelings, and actions that are socially and psychologically influenced during the process of alopecia caused by chemotherapy.

\section{Materials and Methods}

\section{Research design}

This study adopted the exploratory factor research design to understand the psychosocial reactions of the target group suffering from alopecia.

\section{Target group}

The target group comprised patients diagnosed with cancer who have undergone two or more cycles of chemotherapy at hospital A. They were all female (with breast or gynecological cancer) and suffered from alopecia. Written consent for participation in this study was obtained from all participants. The level of alopecia was between one and two on the Criteria for Adverse Events (this was determined by the side-effect grade basis for NCI. Patients in grade 2 of alopecia).

These are the conditions that begin from when the scalp started to show till the hair completely fell out. This means the patients were managing their everyday lives by themselves. The time period for the development of alopecia is within one year from the beginning of hair fall. Moreover, because alopecia is an affliction that influences a person's body image, a difference between how each gender experiences the disease was predicted. Therefore, only women were used as the target group in this study. Patients who could not verbally communicate or had suffered from strong pain due to adverse events caused by their illness or chemotherapy were excluded from the target group.

\section{Data collection time period}

Data were collected from April 8, 2003 to June 30, 2009.

\section{Methods}

Because the psychosocial reactions of patients undergoing chemotherapy and experiencing alopecia are individual and internal, it is important to understand the truth about them. Therefore, the interview timeframe was after the completion of two or more cycles of chemotherapy. The content of the interviews only mattered when the doctor explained to the patients that they needed chemotherapy, when their hair started to fall out, and with respect to their feelings and coping methods when their hair fell out and their scalp became visible. Semistructured interviews were used to investigate this content. Data collection was done in a manner that would not obstruct the patients' lives or treatment schedule, and it was adjusted so that it would not be a burden to them. It was assumed that an obvious psychological change would occur in the target group whose body image has been altered by alopecia resulting from chemotherapy. Thus, there were concerns about patients who experienced a strong sense of loss from the change in their appearance and consequently had psychological reactions. To sufficiently observe and consider these patients, the participantobserver study approach was adopted to collect data while retaining the researcher's role. Observations comprised facial expressions, attitudes, speech, and conduct that were seen in interactions between the patients, medical care providers, and others with the same sickness from when treatment began until it was completed. Immediately after they were made, observations were recorded in the field notebook. Moreover, information related to the target group's age, occupation, medical history, family structure, medical progress, diagnosis name, treatment plan, duration of illness, and information from their doctor was gathered 
from the medical records, all of which was used as the foundational material.

\section{Results}

\section{Summary of the target group}

A summary of the target group is shown in Table 1. The target group was selected from people who were deemed able to participate in this research by their attending physician and outpatient or hospital ward head nurses. A total of 38 female patientswith breast cancer and 27 female patients with gynecological cancer fulfilled these criteria. Of these potential participants, 12 patients fulfilling the requirements for the target group of this research were selected from the two groups. Among these 24 people, data were obtained from 20 patients $(83 \%)$ who were actually interviewed. Analysis was based on this data. Moreover, all members of the target group were undergoing the standard medical treatment that conformed to guidelines.

Psychosocial reactions and phases in the process of alopecia in female patients with gynecological cancer

Interview results of the 20 individuals from the target group were coded according to the psychosocial reactions to the process of alopecia caused by chemotherapy. The reactions were organized into 135 codes. Thirtyone subcategories were then extracted and the data were integrated under 14 labels. These were organized chronologically, and the six phases when the psychosocial reactions changed were clarified. These six phases are shown in Table 2 and are as follows: the reaction right after the doctor's explanation, reaction when the hair starts to fall out, reaction when the hair starts to intensely fall out, reaction when the hair has completely fallen out, reactions to behaviors for coping with alopecia, and reaction to interpersonal human relationships. In the text below, phases are shown as [--], labels are shown as $\{--\}$, and the words of a representative of the target group are shown inside quotation marks.

i) Phase 1 [Reaction immediately after the doctor's explanation] The patient received an explanation of the condition of their disease and chemotherapy. They also learned of the side effects of chemotherapy, including alopecia, and they felt deep psychological stress. However, they still had positive thoughts about life, and many of them gathered the determination to undergo chemotherapy even if their hair fell out. They sufficiently understood the necessity of chemotherapy and said \{my life is more important than my hair falling out $\}$. However, they also expressed a strong shock at the notion of their hair falling out $\}$.

ii) Phase 2 [Reaction when the hair starts to fall out] Two reactions were expressed with regard to the experience of the hair actually falling out extensively. The first reaction was calm and showed no agitation. This reaction was \{I was slightly surprised when my hair fell out just the way I had imagined\}. The second reaction was shock and surprise at the way the hair fell out more than expected. This reaction was $\{\mathrm{I}$ feel threatened by the unimaginable way my hair falls out $\}$.

iii) Phase 3 [Reaction when the hair starts to intensely fall out] There were two main reactions expressed when the patients' hair fell out. The first had no lingering affection for the hair and thought $\{$ As it will all fall out anyway, I decided to bravely say goodbye $\}$. The second reaction involved a strong lingering affection for the hair. This caused a psychologically painful experience that was described strongly as \{a sense of loss for the hair\}.

iv) Phase 4 [Reaction when the hair has completely fallen out] There were three types of reactions recognized when patients experienced complete hair loss. The first emphasized the importance of living and the patients thus gave up on their hair in order to save their life $-\{$ I am abandoning my hair because of my illness $\}$. In the second

Table 1. Summary of the Participants

\begin{tabular}{|c|c|c|c|c|c|}
\hline Target & Age range & Type of Cancer & $\begin{array}{l}\text { Type of Medical } \\
\text { Treatment }\end{array}$ & $\begin{array}{c}\text { Duration of } \\
\text { Alopecia }\end{array}$ & $\begin{array}{c}\text { Behaviors for } \\
\text { Coping with Alopecia }\end{array}$ \\
\hline A & $30 \mathrm{~s}$ & Breast cancer & TXL & 8 & Wig \\
\hline B & $40 \mathrm{~s}$ & Breast cancer & TXL Herceptin & 11 & Wig \\
\hline $\mathrm{C}$ & $30 \mathrm{~s}$ & Breast cancer & CEF & 4 & Hat \\
\hline $\mathrm{D}$ & $60 s$ & Breast cancer & TXL & 5.5 & Wig \\
\hline $\mathrm{E}$ & $50 \mathrm{~s}$ & Breast cancer & TXL Herceptin & 11 & Wig \\
\hline $\mathrm{F}$ & $60 s$ & Breast cancer & TXL & 5 & Wig \\
\hline G & $60 s$ & Breast cancer & TXL & 5.5 & Wig \\
\hline $\mathrm{H}$ & $40 \mathrm{~s}$ & Breast cancer & TXL Herceptin & 9 & Wig \\
\hline I & $40 s$ & Breast cancer & $\mathrm{CEF}$ & 5 & Hat \\
\hline $\mathrm{J}$ & $40 \mathrm{~s}$ & Breast cancer & $\mathrm{CEF}$ & 6.5 & Wig \\
\hline $\mathrm{K}$ & $40 \mathrm{~s}$ & Ovarian cancer & TJ medical treatment & 2.5 & Wig \\
\hline $\mathrm{L}$ & $60 s$ & Endometrial cancer & TJ medical treatment & 2.5 & Hat \\
\hline M & $60 s$ & Endometrial cancer & TJ medical treatment & 3.5 & Wig \\
\hline $\mathrm{N}$ & $60 s$ & Ovarian cancer & $\mathrm{TJ}$ medical treatment & 5.5 & Hat \\
\hline $\mathrm{O}$ & $50 \mathrm{~s}$ & Ovarian cancer & TJ medical treatment & 5.5 & Hat \\
\hline $\mathrm{P}$ & $60 s$ & Endometrial cancer & TJ medical treatment & 4.5 & Wig \\
\hline Q & $60 s$ & Ovarian cancer & $\mathrm{TJ}$ medical treatment & 11 & Wig \\
\hline $\mathrm{R}$ & $50 \mathrm{~s}$ & Endometrial cancer & $\mathrm{TJ}$ medical treatment & 11 & Wig \\
\hline $\mathrm{S}$ & $50 s$ & Endometrial cancer & TJ medical treatment & 4.5 & Wig \\
\hline $\mathrm{T}$ & $30 \mathrm{~s}$ & Ovarian cancer & TJ medical treatment & 3.5 & Wig \\
\hline
\end{tabular}

CEF (Endoxan® Farmorubicinß 5-Fluorouracil@; TJ Medical treatment (Taxol@ Paraplatinß) 
Ishida Kazuko et al

Table 2. Psychological and Social Reactions in the Process of Alopecia in Female Genital Cancer Patients Undergoing Chemotherapy

\begin{tabular}{|c|c|c|}
\hline Phase & Label & Subcategory \\
\hline \multirow[t]{5}{*}{$\begin{array}{l}\text { Reaction after the doctor's } \\
\text { explanation }\end{array}$} & \multirow[t]{3}{*}{$\begin{array}{l}\text { Life more important than hair } \\
\text { falling out }\end{array}$} & $\begin{array}{l}\text { If it will save my life, I will undergo medical treatment even if } \\
\text { it makes my hair fall out. }\end{array}$ \\
\hline & & $\begin{array}{l}\text { I don't want cancer to return, so I will undergo medical treat- } \\
\text { ment despite it making my hair fall out. }\end{array}$ \\
\hline & & $\begin{array}{l}\text { I am not concerned about my hair falling out because the } \\
\text { condition of my disease is bad. }\end{array}$ \\
\hline & \multirow[t]{2}{*}{ Strong shock at hair falling out } & $\begin{array}{l}\text { My hair falling out is such a shock that I cannot think of } \\
\text { anything. }\end{array}$ \\
\hline & & $\begin{array}{l}\text { It is more painful that my hair to fall out due to the treatment } \\
\text { than when I was told I had cancer. }\end{array}$ \\
\hline \multirow[t]{5}{*}{$\begin{array}{l}\text { Reaction when the hair } \\
\text { starts to fall out }\end{array}$} & \multirow[t]{2}{*}{$\begin{array}{l}\text { A small surprise at hair falling } \\
\text { out as imagined }\end{array}$} & $\begin{array}{l}\text { I am not worried because my hair fell out just how I thought } \\
\text { it would. }\end{array}$ \\
\hline & & I was prepared for my hair to fall out so I am fine. \\
\hline & \multirow{3}{*}{$\begin{array}{l}\text { Threatened by how hair falls out } \\
\text { beyond imagination }\end{array}$} & I am surprised by the unexpected way my hair falls out. \\
\hline & & I am surprised by the terrible way my hair falls out. \\
\hline & & I am surprised by the speed that it falls out. \\
\hline \multirow{5}{*}{$\begin{array}{l}\text { Reaction when the hair } \\
\text { starts to intensely fall out }\end{array}$} & \multirow{2}{*}{$\begin{array}{l}\text { Bravely cut it off because it falls } \\
\text { out anyway }\end{array}$} & Since it will all fall out anyway, I will bravely cut it off. \\
\hline & & I will give myself a new start as my hair is going to fall out. \\
\hline & \multirow{3}{*}{$\begin{array}{l}\text { Sense of loss towards hair falling } \\
\text { out }\end{array}$} & I am still attached to my hair that is going to fall out. \\
\hline & & I am sad that my hair will fall out. \\
\hline & & I cry that it might not grow back. \\
\hline \multirow{5}{*}{$\begin{array}{l}\text { Reaction when the hair has } \\
\text { completely fallen out }\end{array}$} & \multirow[t]{2}{*}{ Giving up hair for recovery } & I will give it up in exchange for my life. \\
\hline & & $\begin{array}{l}\text { I will give up on my hair because I want to recover more than } \\
\text { anything else. }\end{array}$ \\
\hline & \multirow{2}{*}{$\begin{array}{l}\text { Giving up hair out of inescapable } \\
\text { harsh reality }\end{array}$} & I will give up because thinking about it won't help. \\
\hline & & I cry and cry and give it up \\
\hline & $\begin{array}{l}\text { Giving up treatment where hair } \\
\text { falls out }\end{array}$ & I don't want any treatment that causes my hair to fall out. \\
\hline \multirow{5}{*}{$\begin{array}{l}\text { Reaction to behaviors for } \\
\text { coping with alopecia }\end{array}$} & \multirow[t]{2}{*}{ Retaining individuality } & I wear a hat or wig and feel fashionable. \\
\hline & & I feel like the wig is part of my body. \\
\hline & \multirow[t]{3}{*}{ Sense of stigma no matter what } & Wearing a wig, I worry about people staring. \\
\hline & & Even if I wear a wig, I cannot accept myself. \\
\hline & & $\begin{array}{l}\text { Wearing a wig makes me feel like I am a cancer patient and } \\
\text { so I have a sense of stigma. }\end{array}$ \\
\hline \multirow{6}{*}{$\begin{array}{l}\text { Reaction to human } \\
\text { relationships }\end{array}$} & \multirow[t]{2}{*}{ Maintaining human relationships } & I can talk about losing my hair without hiding it. \\
\hline & & $\begin{array}{l}\text { I can have fun with my friends and family even if my hair } \\
\text { falls out. }\end{array}$ \\
\hline & \multirow[t]{3}{*}{$\begin{array}{l}\text { Reduction of human relation- } \\
\text { ships }\end{array}$} & $\begin{array}{l}\text { I don't want to see people if I don't have hair, so I just go } \\
\text { between my house and the hospital. }\end{array}$ \\
\hline & & $\begin{array}{l}\text { I don't meet anyone outside of the family because others } \\
\text { might think I have cancer without my hair. }\end{array}$ \\
\hline & & I don't want to see people because I don't have hair. \\
\hline & Isolation & I cannot even tell my husband that my hair fell out. \\
\hline
\end{tabular}

reaction, patients confronted the inescapable reality and gave up on the hair even though they wished it would not fall out. This was expressed as \{I am abandoning my hair to the harsh and inescapable reality. $\}$. The third reaction comprised a sense of sorrow over the hair loss. Patients who had this reaction were unable to accept reality and they abandoned the medical treatment that was resulting in hair loss. This was expressed as II am abandoning medical treatment in which the hair falls out $\}$.

v) Phase 5 [Reactions to behaviors for coping with alopecia] The patients' reactions to themselves wearing hats or wigs when their hair had completely fallen out were divided into two types. The first reaction to these coping methods was to perceive them positively and treat them like part of their own body. This reaction led to saying things like "I look young" and "It's pretty." This reaction 


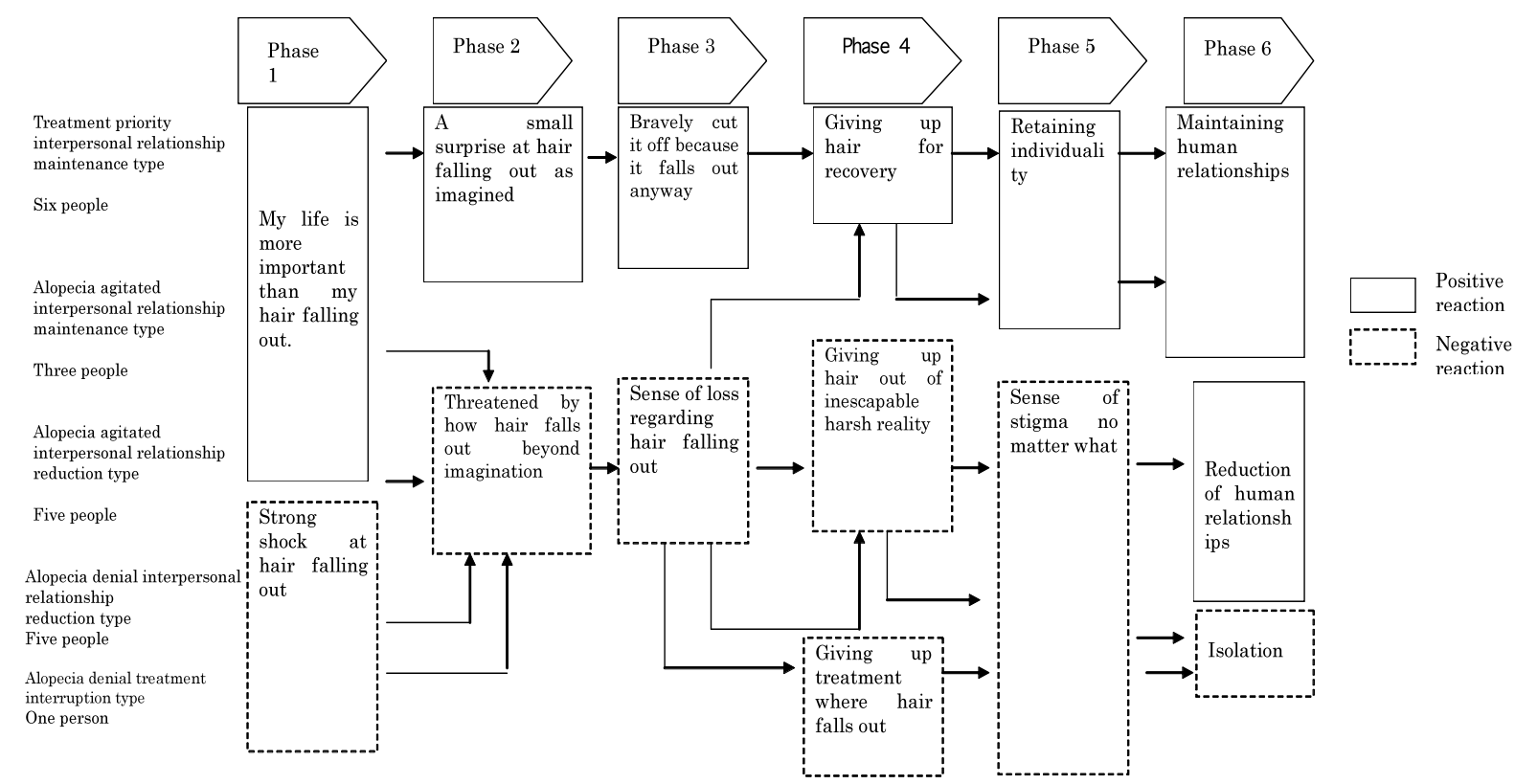

Figure 1. Psychological and Social Reaction Patterns Associated with Alopecia in Female Patients with Genital Cancer Undergoing Chemotherapy

was labeled \{maintaining individuality . The second reaction was labeled \{no matter what, I feel inferior\}. This reaction led to patients not accepting themselves and saying things like "I have coped with losing my hair by putting on a wig or a hat, but even when I wear a wig, I feel like people are looking at me" and "being thought of as a cancer patient is awful."

vi) Phase 6 [Reaction to interpersonal human relationships] There were three categories of reactions related to interpersonal relationships that were affected by alopecia. The first reaction was \{maintaining interpersonal relationships $\}$. In this case, the patient talked about everything, such as getting cancer and undergoing medical treatments, to everyone, such as friends and family. The patient interacted with as many or comparatively more people than prior to getting cancer. The second reaction was the \{reduction of interpersonal relationships\}. In this case, the patient did not talk to others about their hair loss and tried to ensure that no one knew about them suffering from cancer. They only interacted with their very close friends and family and were hesitant about leaving the house to go to the hospital. The third reaction was \{isolation\}, when the patient did not want anyone other than their husband to know about their cancer and hair loss.

Psychosocial reaction patterns to the process of alopecia in female gynecological cancer patients

After the analysis concluded, labels for psychosocial reactions to the process of alopecia for individuals in the target group were organized on the basis of the treatment process and timeframe (Figure 1). A comparative examination was then conducted. As each person in the target group had these reactions in the order that they reached a phase, it was possible to derive five types of patterns. These types of patterns are as follows: the treatment priority interpersonal relationship maintenance type, the alopecia agitated interpersonal relationship maintenance and reduction types, the alopecia denial interpersonal relationship reduction type, and the alopecia denial treatment interruption type.

Treatment priority interpersonal relationship maintenance type (six people) F.L.O.Q.R.S

In phase 1 , this type of patient thought my life is more important than my hair falling out , and they faced treatment having decided that life is more important than the side effects of chemotherapy. In phase 2, they were not agitated and said II was slightly surprised when my hair fell out just the way I had imagined\}. In phase 3, the reaction to their hair quickly falling out was saying \{since it will all fall out anyway, I decided to bravely say goodbye $\}$. In phase 4 , they strongly desired their own recovery and looked toward the future, saying $\{\mathrm{I}$ am abandoning my hair for my recovery $\}$. In phase 5 , this type of patient perceived themselves in a positive light by being able to \{retain their individuality\} through wearing wigs or hats. In phase 6 , the patient \{maintains interpersonal human relationships $\}$ through enjoyment of their hobbies in spite of having cancer and having their hair fall out.

\section{Alopecia agitated interpersonal relationship maintenance type (three people) H.J.P}

In phase one, this type of patient showed the same reaction as the treatment priority interpersonal relationship maintenance type. They said that my life is more important than my hair falling out $\}$. However, in phase 2 , they \{feel threatened by the unimaginable way their hair falls out\}, and this can be seen in the statement "I was so surprised at it falling out when I washed it so much that my heart was racing." In phase 3, the patient expressed \{a sense of loss for their hair\}, shown in the statements "I have lingering affection for my hair that is falling out" and "I am sad that my hair is falling out." Subsequently, in phase 4, they gave up on their hair, thinking "it is my hair in exchange for my life" and \{I'll give up on my hair for my illness $\}$. In phase 5 , this type of patient dealt with 
alopecia by wearing wigs that they considered a part of their body, and they thus \{retain individuality\}. In phase 6 , they showed they could \{maintain interpersonal human relationships.\}

Alopecia agitated interpersonal relationship reduction type (five people) B.E.I.M.N

Until phase 3 , this type of patient is similar to the alopecia agitated interpersonal relationship maintenance type. In phase 1 , they expressed that my life is more important than my hair falling out\}, represented by the statement "I think suppressing the cancer is more important than my hair falling out." In phase 2, they had the reaction of ffeeling threatened by the unimaginable way their hair falls out as exemplified by the statement "I am surprised at how much hair is in the wash basin every time I wash it." However, in phase 4, they showed the reaction of abandoning their hair to the harsh and inescapable reality\} expressed in the statement " $I$ 've given up because even if I struggle, all of my hair will completely fall out." In phase 5, this type of patient wore wigs or hats, but they could not accept themselves without hair. They $\{$ feel inferior no matter what they do\}. In phase 6 , the \{reduction of human relationships\} is reflected in their hesitation to leave the house and go to and from the hospital.

Alopecia denial interpersonal relationship reduction type (five people) A.D.G.K.T

In phase 1, patients differed from reaction types 1-3. They expressed a negative reaction towards alopecia and were \{very shocked by the notion of their hair falling out \}. This was exemplified in the following statements: "on top of the shock of being told I had cancer, when I was told I would lose my hair, I couldn't hear anything else," and "once I was out of surgery and I thought that was the end of it, I was bewildered when I was told to undergo treatment in which my hair would fall out." From phase 2 onwards, this type of patient showed the same reactions as the alopecia denial interpersonal relationship reduction type.

Alopecia denial treatment interruption type (one person) $C$

The psychosocial reaction patterns shown until phase 3 were the same as with the alopecia denial interpersonal relationship reduction type, but in phase 4 , they could not accept the reality of the situation and expressed the decision to \{abandon the medical treatment in which the hair falls out $\}$. This was exemplified in the statement " $a t$ this rate, all of my hair falling out will make me so sad I don't know what to do, so I asked the doctor to suspend the treatment that makes my hair fall out." In phase 5, these patients demonstrated the negative reaction of \{feeling a sense of inferiority no matter what they did\}. This was shown in the statement "when I wear a wig, I feel exactly like I'm a cancer patient." Moreover, in phase 6 , they demonstrated the reaction of being \{isolated $\}$ in their interpersonal relationships. This was expressed in the statement "I don't want anyone to know that I have cancer, and when I walk around in a wig outside of my house, I don't meet with anyone because I don't want to be thought of as a cancer patient."

\section{Discussion}

While female patients suffering from gynecological cancer and undergoing chemotherapy expressed some standardized psychosocial reactions, there were also differences seen. Therefore, the psychosocial reaction patterns of each phase will be considered and nursing intervention will be examined.

Concerning the Psychosocial reaction patterns to the process of alopecia in female gynecological cancer patients, in phase 1 , patients received an explanation of the necessity and side effects of chemotherapy. Both positive and negative psychosocial reactions to the side effect of alopecia were expressed. Some patients showed a positive reaction to alopecia by accepting that chemotherapy is a necessary treatment in order to live. Conversely, other patients understood the necessity of chemotherapy but showed a negative reaction to the acknowledgment that their appearance would change resulting from unexpected alopecia. This reaction is controlled by how the patient accepts the news of medical treatment. This psychosocial reaction occurs in the imagination to the unknown experience of alopecia.

In phase 2, the patients reacted to their hair actually starting to fall out. It became clear that when there was little sense of discrepancy between the imaginary alopecia and actual alopecia resulting from chemotherapy, the patients showed a positive reaction. It also became clear that when a large discrepancy was acknowledged, the patients showed a negative reaction.

In phase 3 , the target patients who showed a positive reaction in phase 2 had no sense of attachment to their hair. They reacted by saying \{since it will all fall out anyway, I decided to bravely say goodbye $\}$. The target patients who showed a negative reaction of ffeeling threatened by the unimaginable way their hair falls out $\}$ had a strong sense of attachment and were fixated on their hair. They expressed a \{sense of loss for their hair that will fall out\}. This experience of loss is similar to the one faced by breast cancer patients (Mitsuko et al., 1992). However, patients who suffer from alopecia due to chemotherapy are told the name of their illness. When they have yet to accept themselves as having cancer, they are the delivered another blow from the onset of alopecia. This is considered a double loss experience.

In phase 4 , the target patients had experienced the complete loss of their hair, and they suffered a mental shock. These patients were in a situation that could not be accepted without negativity, and they reacted by giving up. After these patients looked at themselves after having lost all their hair, they gave up on it. The mentality of trying to accept themselves after they had changed in a negative way can be called a positive reaction. However, patients who found it painful to look at themselves while suffering from alopecia expressed the choice of \{abandoning the medical treatment in which the hair falls out.\} The change in appearance that accompanies chemotherapy-induced alopecia caused unbearable suffering, and it became clear that some patients needed to suspend necessary medical treatments to continue living. 
In phase 5 , all patients in the target group had coping mechanisms like wigs and hats to compensate for their altered body image. However, patients demonstrated both positive and negative reactions to the awareness of their own image resulting from these coping mechanisms. Alopecia causes a change in appearance that anyone can see. It is a side effect that brings about significant difficulties with one's body image (Bello and McIntire, 1995; McGarvey et al., 2011).

In phase 6 , the target patients who demonstrated the reaction \{retaining individuality when dealing with the coping mechanisms in phase 5 could maintain their interpersonal human relationships. On the other hand, those who demonstrated the reaction of \{feeling inferior no matter what was done $\}$ clearly became isolated or saw a decrease in their interpersonal relationships.

2. Suggestions on nursing care for female gynecological cancer patients in the process alopecia undergoing chemotherapy

Patients with alopecia due to chemotherapy and who have just been told they have cancer are thought to experience a double loss. This is because they have not yet accepted themselves as having cancer, and another blow is delivered to them in the form of alopecia that causes them to see themselves as a cancer patient.

Results of this research show that support for these patients is insufficient. It is not enough to simply tell them to "wear wigs when their hair falls out," or to try to cheer them up by saying their "hair will come back very soon." This research suggests that psychosocial support is necessary.

Patients with chemotherapy-induced alopecia anticipate a change in their outward appearance after heard the doctor's explanation and are quite shocked about their image. In the Vandegrift (1994) wig program, before a patient underwent chemotherapy for cancer, patients were asked to discuss feelings that were difficult to imagine and how they would look with no hair. Afterward, nurses intervened by giving them basic information about chemotherapy, which reportedly reduced the shock of alopecia. This leads us to believe that it is possible to reduce the shock of the actual process of alopecia by having nurses confirm the patient's reaction after the doctor's explanation and prior to their chemotherapy. At this time, nurses can listen closely to the patient's painful thoughts and accept them. Looking one's self in the eyes after actually losing all of one's hair is a painful experience in which it is very difficult to accept the major changes in one's self. Alopecia causes considerable changes in one's outward appearance and can cause the reaction of having a sense of being negatively judged by society. One reason that breast cancer patients (Mitsuko et al., 1992) who have experienced the permanent loss of their breasts through surgery do not want their bodies to be seen by others is their concern with other people's assessments and stares. The experience of alopecia is analogous to this. For people who find value in their own beauty and completeness, the experience of alopecia can make them feel like their appearance without hair is ugly. This can lead to a degraded concept of self, often making them feel inferior. A person's body image is formed through experiences and perception related to their own body. It is thought to be a notion that is constantly changing and being revised through interactions. Our research also showed that the patient's change in body image brought about by alopecia was frequently accompanied by hesitation to leave home, avoiding interactions with other people, and becoming negative (Kazuko et al., 2004). In the process of alopecia, it is useful to give support to improve their self-image and increase their sense of self-worth. To that end, it is useful for them to wear wigs and fashionable hats and attend peer support groups with other patients going through a similar ordeal.

Nursing support and reaction patterns of female gynecological cancer patients in the process of alopecia undergoing chemotherapy

In the psychosocial reactions to the process of alopecia by female gynecological cancer patients undergoing chemotherapy, we see a relationship between individual acknowledgment, medical providers, family, self-image, and relationships with friends. Moreover, if a patient accepts that they have cancer and assertively works toward medical treatment, they can perceive themselves positively even with alopecia.

Patients belonging to the treatment priority interpersonal relationship maintenance type were consistent from phases 1 to 6 . They demonstrated the positive reaction of thinking that the alopecia that accompanies chemotherapy (an effective medical treatment for survival) is something they must bear in exchange for their life. This agrees with Nagata's (2001) results regarding target patients who are adaptable. These hematopoietic stem cell transplant patients in outpatient programs cope through assertive actions and by assigning positive meaning to their disease. Target patients who demonstrate these types of positive reactions can undergo medical treatments in a forwardfacing manner by constantly saying positive things so they can take assertive actions.

The patients belonging to alopecia agitated interpersonal relationship maintenance type demonstrated different reactions compared with those of the treatment priority interpersonal relationship maintenance type. In phase 1, they expressed strong shock at the idea of losing their hair in their "reaction after they received the doctor's explanation." In phase two, their "reaction when their hair starts to fall out" was expressed as feeling threatened by the unimaginable way their hair would fall out. In phase three, they experienced a feeling of loss for their hair that will fall out as their "reaction when the hair start to intensely fall out." These patients were characterized by the shock they sustain from their self-image that is difficult to accept due to alopecia caused by anti-cancer drug treatment. This type of patient experienced a threat and feeling of loss when their hair actually fell out, but they accept the anticancer drug treatments as necessary to live. It became clear that for patients of the treatment priority interpersonal relationship maintenance type and the alopecia agitated interpersonal relationship maintenance type, interpersonal relationships were maintained throughout the process of alopecia by being able to demonstrate positive reactions in phase 4 and by positively handling the "coping mechanism for alopecia" in phase 5. This occurred even if there were 


\section{Ishida Kazuko et al}

some disturbances and agitation along the way. Therefore, nurses should carefully observe the cancer patient's reaction when their hair completely falls to determine if it is positive. Careful observation by nurses is linked to supporting the continuation of treatment.

The patients belonging to the alopecia agitated interpersonal relationship reduction type demonstrated the same reactions as patients of the alopecia agitated interpersonal relationship maintenance type for phases 1 to 3 , but in phase 4 in the process of alopecia, they gave up as a coping mechanism when they looked at themselves after their hair had actually fallen out. In phase 5, they developed a negative self-image when their hair had actually fallen out and could not accept the change in themselves. This was expressed as a sense of indebtedness, and this clearly led to fewer interpersonal relationships. From the viewpoint of psychosomatic medicine, the body image should make human being's body and mind as one. Psychosomatic medicine argues for a close relationship between the mind and the body (Fujisaki 1996). Alopecia is an experience that influences a person's body image; therefore, its psychological damage is immeasurable. This psychological damage clearly becomes a sense of indebtedness, and an experience always results in fewer interpersonal relationships.

Excluding phase 1, the alopecia denial interpersonal relationship reduction type patients demonstrated the same reactions as the alopecia agitated interpersonal relationship reduction type patients. However, in phase 1 and the "reaction after the doctor's explanation," such patients were characterized by strong shock at the notion of losing their hair. This was the reaction immediately after the doctor explained chemotherapy as a medical treatment resulting in hair loss. The patients imagined a self-image with their hair falling out and were shocked. After this, these patients demonstrated negative reactions in all phases. It is assumed that while they think that if they do not undergo anti-cancer drug treatments, they will not live, and thus do not want to undergo these treatments. Yet, they continue the treatments even while being in a state of constant conflict. It became clear that alopecia caused by medical treatments reduced interpersonal relationships in everyday life and shrank the patient's world.

Moreover, patients belonging to the alopecia denial treatment interruption type had the same reactions as those belonging to alopecia denial interpersonal relationship reduction type except for the reaction in phase 4 when their hair had completely fallen out. The reaction of the former patients was "abandoning medical treatment in which the hair falls out." However, the characteristic of such patients is that in phase 4, they cannot accept themselves with alopecia and suspend medical treatment that is their only hope to live. Alopecia caused by anti-cancer drug treatment (even if this is their only hope of survival) can give the patient a psychologically unbearable shock from the change in body image and result in the suspension of cancer treatments. Nurses may easily believe that treatment-induced alopecia will quickly disappear once treatment is suspended, but they must consider that some patients would exchange their life to suspend medical treatment.

\section{Acknowledgements}

I would like to express my sincere gratitude to all of the staff members at hospital A and to all members of the target group who cooperated in the investigation undertaken for this research.

\section{References}

Batchelor, D (2001), Hair and cancer chemotherapy: consequences and nursing care-a literature study, Eur $J$ Cancer Care, 10, 147-163.

Bello LK, McIntire SN (1995), Body image disturbances in young adults with cancer: implication for the oncology clinical nurse specialist, Cancer Nurs, 18, 138-2.

Bernard M, Brignone M, Adehossi A, et al (2011). Perception of alopecia by patients requiring chemotherapy for nonsmall-cell lung cancer: a willingness to pay study. Lung Cancer, 72, 114-8.

Can G, Demir M, Erol O, Aydiner A (2013). A comparison of men and women's experiences of chemotherapy of chemotherapy-induced alopecia. Eur J Oncol Nurs, 17, 255-60.

Carelle N, Piotto E, Bellanger A, et al. (2002). Changing patients of the side effects of cancer chemotherapy. Cancer, 95, 155-163.

Dean, J, Salmon, S.1 (1979). Prevention of doxorubicin-induced hair loss with scalp hypothermia. N Engl J Med, 30, 1427-9.

Ekwall EM, Nygren LM, Gustafsson AO, Sorbe BG (2013). Determination of the most effective cooling temperature for the prevention of chemotherapy-induced alopecia. Molec Clinical Oncol, 1, 1065-71.

Frith H, Harcourt D, Fussell A (2007). Anticipating an altered appearance: Women undergoing chemotherapy treatment for breast cancer. Eur J Oncol Nursing, 11, 385-391.

Fujisaki K (1996). Development of "Body Image Assessment Tool." J Japan Acad Health Behavioral Sci, 5, 178-99.

Gregory RP, Cooke T, Middleton J, et al (1982). Prevention of doxorubicin-induced Alopecia by scalp hypothermia: Relation to degree of cooling. Br Med J, 284, 1674

Hamada M, Ohji T, Fukui R, Tanno K, Kasamatsu T, Ebina $M$ (2007). Coping behavior and feelings in middle-aged men who have experienced hair loss induced by cancer chemotherapy. Kobe City College Nursing, 11, 19-26.

Hilton S, Hunt K, Emslie C, et al (2008). Have men been overlooked? A comparison of young men and women experiences chemotherapy of chemotherapy-induced alopecia. Psycho-oncology, 17, 577-583.

Kanda K, Iida M, Nakamura M (1998). Study on the gustatory change of cancer chemotherapy patients: Part II the relationship between chemotherapy side effects and gustatory change. Kitakanto Medical J, 6, 455-459.

Kaoru Fujisaki (2000). An integrative literature review about body-image intervention program and effects-analysis and synthesis of evaluation research using substruction method. J Nurs Res, 33, 73-87.

Kazuko I, Junko I, Mami N, et al (2004). Concerns and treatment continuation factor of outpatient chemotherapy of breast on the patients daily life. Ann Gunma University School Health Sciences, 25, 42-53.

Keiko M, Noriko M, Maki M, et al (2013). The effects of chemotherapy-induced alopecic experience on daily living. $J$ Nursing Invest, 11, 14-23.

Kim IR, Cho J, Choi EK, et al (2012). Perception, attitudes, preparedness, and experience of chemotherapy-induced 
alopecia among breast cancer patients: a qualitative study. Asian Pac J Cancer Prev, 13, 1383-8.

Komen MM, Smorenburg CH, Van den hurk CJ, Nortier JW (2013). Factors influencing the effectiveness of scalp cooling in the prevention of chemotherapy-induced alopecia. The Oncologist. 885-91.

Lemieux J, Maunsell E, Provencher L (2008). Chemotherapyinduced alopecia and effects on quality of life among women with breast cancer: a literature review. Psycho-Oncol, 17, 317-28.

McGarvey EL, Leon-Verdin M, Baum LD, et al (2011). An evaluation of a computer imaging program to prepare women for chemotherapy-related alopecia. Psycho-Oncol, 19, 756-66.

Mitsuko M, Fusae M, Toshie K, et al (1992). Longitudinal studies of psychological adjustment for mastectomy patients (1)-Psychological reactions from pre-surgery to 3 years postsurgery, J Japan Soc Nursing Res, 15, 20-28.

Mols F, Van den Hurk CJ, Vingerhorts AJ, et al (2008). Scalp cooling to prevent chemotherapy-induced hair loss: practical and clinical considerations. Support Care Cancer, 17, 181-9.

Nahoko S, Mitiko M (2009). Pain perceived by outpatients receiving chemotherapy for cancer. J Jpn Soc Cancer Nurs, 23, 53-60.

Nolte S, Donnelly J, Kelly S, Conley P, Cobb R (2006). A randomized clinical trial of a videotape in intervention for woman with chemotherapy-induced alopecia: a gynecologic oncology group study. Oncol Nurs Forum, 33, 305-311.

Roe, H (2011). Chemotherapy-induced alopecia: advice and support for hair loss. Br J Nurs, 9, 4-11.

Satoko Nagata (2001). Research on Factors Related to the Psychosocial Adjustment of Adult Outpatients with Hematological Malignancies. Journal of Japan Society of Cancer Nursing, 15, 5-15.

Vandegrift KV,CRNI (1994). The Development of an Oncology Alopecia Program. J Intravenous Nursing, 17, 79-82.

Van den Hurk CJ, Mols F, Vingerhoets AJ, et al (2010). Impact of alopecia and scalp cooling on the wellbeing of breast cancer patients. Psycho-Oncol, 19, 701-809.

Van den Hurk CJ, Peerbooms M, van de Poll-Franse LV, et al (2012). Scalp cooling for hair preservation and associated characteristics in 1441 chemotherapy patients- results of the Dutch Scalp Cooling Registry. Acta Oncol, 51, 497-504.

Van den Hurk CJ, Breed WP, Nortier JW (2012). Short postinfusion scalp cooling time in the prevention of docetaxelinduced alopecia. Support Care Cancer, 20, 3255-60.

Williams J, Wood C, Cunningham-Warburton C (1999). A narrative study of chemotherapy-induced alopecia. Oncology Nursing Forum, 26, 1463-9. 